\title{
Optimum Operating Conditions of Drinking Water Treatment System for Fluoride Removal using High Adsorption Bone Char
}

\author{
Min-Soo Maeng ${ }^{\oplus} \cdot$ Jung-Seop Byun $\cdot$ Hyo-Jin Park $\cdot$ Gwy-Am Shin ${ }^{\dagger}$ \\ Department of Environmental and Safety Engineering, Ajou University
}

(Received July 31, 2020; Revised October 19, 2020; Accepted October 23, 2020)

Objectives: Bone char is used in many eastern countries in Africa to remove high levels of fluoride from groundwater. However, due to the low adsorption efficiency of bone char, it is necessary to replace bone char frequently, which cause significant burden to the people in those areas. In this study, we developed a water treatment system to remove high level of fluoride in groundwater using a high efficiency bone char.

Methods: In order to make a high efficiency bone char, cow bones were washed, dried and cut into small pieces. Then the bones were burned for 1,3 and 5 hours at 350,450 and $550^{\circ} \mathrm{C}$ in electric furnaces. After that, the burned bones were sieved with $600 \sim 2,000 \mu \mathrm{m}$ to match the size of bone char being used in Ethiopia. Surface analysis of bone char was performed using SEM and BET. The removal efficiency of bone char was conducted with various level of turbidity, TOC, and fluoride concentration for 90 minutes under the flow rate conditions of $100,200,300$, and $400 \mathrm{~L} /$ day with an initial fluoride concentration of $4.8 \mathrm{mg} / \mathrm{L}$.

Result and Discussion: There was a significant difference between the bone char from Ethiopia and our study in terms of their surface roughness and specific surface area according to SEM and BET analysis. The adsorption capacity of the bone char produced in this study was $3.7 \mathrm{mg} \mathrm{F} / \mathrm{g}$, compared to $1 \mathrm{mg} / \mathrm{L}$ from the one from Ethiopia. In terms of turbidity and organic matter removal with column test, $200 \mathrm{~L} / \mathrm{d}$ showed the shortest operating time to reach turbidity of less than $0.5 \mathrm{NTU}$, and was an effective operation for TOC removal. However, It took the longest to $1.5 \mathrm{mg} / \mathrm{L}$ of fluoride after breakthrough under $100 \mathrm{~L} / \mathrm{d}$ operating conditions. In terms of operating time, bed volume, and energy efficiency, $100 \mathrm{~L} / \mathrm{d}$ was found to be an effective operating condition.

Conclusions: We developed a high efficiency bone char in this study with modification of its production process and tested it at various operating conditions. Our study showed that the bone char developed in this study is about 4 times more effective than traditional bone char and it is most effective at operation with low flow rates. Column operation is most effective at $100 \mathrm{~L} / \mathrm{d}$ for fluoride removal under operating time and bed volume and energy efficiency. Therefore operating condition of drinking water treatment system for the fluorine removal using bone char in developing countries is effective in low flow rate operation.

Keywords: Fluoride Removal, Bone Char, Developing Country, Operating Condition, Appropriate Technology

The Korean text of this paper can be translated into multiple languages on the website of http://jksee.or.kr through Google Translator. 


\title{
연구논문
}

\section{고흡착 골탄을 이용한 불소 제거용 수처리 시스템의 최적 운전 조건}

\author{
맹민수 ${ }^{\oplus} \cdot$ 변정섭 · 박효진 · 신귀암 ${ }^{\dagger \odot}$
}

아주대학교 환경안전공학과

목적 : 에티오피아에서는 지하수 불소 제거를 위해서 골탄을 이용하고 있지만, 흡착 효율이 낮아 잦은 교체비용의 부담을 안고 있다. 또한, 처리수에 탁도와 유기물이 함유되어 식수의 안전성이 떨어진다. 이에 본 연구에서는 현지 에서 생산 가능한 고흡착 골탄을 개발하였으며 초기 탁도 및 유기물 저감을 위한 최적의 운전조건을 도출하였다.

방법 : 뼈를 씻어 건조시킨 후 내부까지 태워질 수 있도록 절단하여 전기로에서 $350,450,550^{\circ} \mathrm{C}$ 에서 온도별로 1 , 3,5 시간을 태워 골탄을 제작하였다. 태워진 골탄들은 에티오피아 현지에서 운영되는 골탄 크기인 $600 ~ 2,000 \mu \mathrm{m}$ 로 분쇄하여 실험하였다. SEM과 BET를 이용해 골탄 표면 분석을 수행하였으며, 회분기 실험를 통해 kinetic, isotherm 흡착 실험을 하였다. 컬럼실험은 초기 불소 농도 $4.8 \mathrm{mg} / \mathrm{L}$ 에서 $100,200,300,400 \mathrm{~L} / \mathrm{day}$ 의 유속 조건으로 90 분 운 전하면서 탁도, TOC, 불소 농도 변화를 확인하였다.

결과 및 토의: 최적의 골탄 제조 조건으로 $450^{\circ} \mathrm{C}$ 에서 3 시간 태우는 것이 탁도와 유기물 제거 측면에서 효과적이었 다. SEM, BET 분석을 통해서 골탄의 표면 거칠기와 비표면적 특징이 불소 흡착효율에 영향을 미쳤다. 회분기 실 험을 통해서 제조된 골탄의 흡착능이 $3.7 \mathrm{mg} \mathrm{F} / \mathrm{g}$ 으로 확인되었다. 컬럼 실험에서는 $200 \mathrm{~L} / \mathrm{d}$ 은 $0.5 \mathrm{NTU}$ 미만의 탁 도에 도달하는데 가장 짧은 시간을 보여주고 있으며, $\mathrm{TOC}$ 를 제거할 때 가장 작은 처리수로도 가능하였다. 하지만, $100 \mathrm{~L} / \mathrm{d}$ 에서 $1.5 \mathrm{mg} / \mathrm{L}$ 의 불소에 도달하는 운전시간은 80 분으로 가장 길었다. 그래서 운전시간, bed volume, 에너 지 효율 측면에서 $100 \mathrm{~L} / \mathrm{d}$ 가 효과적인 운전조건인 것으로 나타났다.

결론: 컬럼을 $100 \mathrm{~L} / \mathrm{d}$ 에서 운전할 때 불소제거 측면에서 효과적인 운전조건이다. 그래서 개발도상국에서 골탄을 이용한 불소 제거 정수처리 시설은 저유량으로 운전하는 것이 효과적이다.

주제어: 불소제거, 골탄, 개발도상국, 운영조건, 적정기술

\section{1. 서론}

동아프리카 지역에 위치한 에티오피아, 탄자니아, 케냐 등 은 Rift Valley에 위치하고 있어 지하수에서 고농도 불소가 검출된다. ${ }^{1)}$ 아프리카 주민들의 약 $75 \%$ 가 지하수를 주요 식 수원으로 이용하고 있기 때문에 고농도 불소에 쉽게 노출되 고 있다. ${ }^{2)}$ 불소가 $1.5 \sim 4 \mathrm{mg} / \mathrm{L}$ 이면 치아 불소증을 유발하고, $4 \mathrm{mg} / \mathrm{L}$ 이상에서는 골격불소증을 유발하기 때문에 WHO (World Health Organization)는 불소 음용수 수질 기준을 1.5 $\mathrm{mg} / \mathrm{L}$ 이하로 권장하고 있다. ${ }^{3)}$ 하지만 대부분의 동아프리카 지역에서 지하수의 불소 농도가 고농도로 검출되기 때문에 건강상 문제가 발생되고 있다. ${ }^{4)}$ 불소 제거를 위한 다양한 처리방법으로는 응집/침전, 전기투석, 이온교환, 역삼투, 흡 착 등이 있다. ${ }^{5-10)}$ 응집/침전 방법은 운영이 편리하지만 지속 적인 응집제 구매 비용과 발생 슬러지 처리 문제로 2 차 오
염 문제가 있다. ${ }^{6}$ 전기투석, 이온교환, 역삼투는 높은 제거 효율을 갖고 있지만, 운영 및 유지보수 비용이 높고 전문운 영능력이 요구된다. ${ }^{7,10)}$ 흡착은 불소 제거효율이 낮지만 가 장 널리 사용되는 방법으로 운영 및 유지보수 비용이 저렴 하여 경제적이고 설계 및 작동이 간소하다. ${ }^{7-10)}$ 따라서 개발 도상국에는 흡착 기술이 불소 제거에 있어서 적절한 수처리 기술이다. ${ }^{8,10)}$ 불소 흡착제로 활성알루미나, 인산삼석회, 제올 라이트, 벤토나이트, 골탄과 같은 저가 재료의 흡착제들이 연 구되었다. ${ }^{8,10)}$ 이 중 흡착 성능이 가장 좋은 불소 흡착제는 동 물의 뼈를 태워 만든 골탄이다. ${ }^{8)}$ 뼈의 65 70\%는 무기물인 Hydroxyapatite (HAP, $\left.\mathrm{Ca}_{10}\left(\mathrm{PO}_{4}\right)_{6}(\mathrm{OH})_{2}\right)$ 로 구성되었으며, ${ }^{8,11)}$ $\mathrm{HAP}$ 를 구성하고 있는 $\mathrm{OH}^{-}$가 $\mathrm{F}^{-}$와 치환되어 불소를 제거 할 수 있다. ${ }^{1213)}$ 특히, 골탄은 주변에서 쉽게 구할 수 있고 폐 기물을 이용한다는 이점을 갖는다. ${ }^{8)}$ 아프리카 에티오피아에 서는 골탄으로 불소를 흡착 제거하는 정수시설을 운영하고 
있다. 하지만 현재 사용 중인 골탄은 흡착능 약 $1 \mathrm{mg} \mathrm{F} / \mathrm{g}$ 인 저흡착 골탄이며, 약 3 개월의 짧은 교체주기를 갖고 있다. 그래서 골탄 교체비용에 따른 경제적 손실이 발생하며, 지 속가능한 식수 제공에 문제가 야기된다. 그리고 저품질 골 탄으로 인해 처리수의 탁도 유발과 유기물로 인한 색도 발 생이 식수에 영향을 미친다. ${ }^{14)}$ 그렇기 때문에 개발도상국에 서는 불소 제거를 위해 저흡착 골탄을 개량한 고흡착 골탄 이 요구된다. 골탄의 흡착능을 높이기 위해 불소와의 경쟁 이온, 골탄의 최적 $\mathrm{pH}$ 및 온도, 골탄의 세륨혼합, 황산알루 미늄코팅, 은코팅 등 다양한 연구가 진행되었다. ${ }^{15-18)}$ 이처럼 고효율 고흡착 골탄 연구는 대부분 실험실 규모에만 국한된 것으로 개발도상국 현지에 적용 가능성이 낮거나, 현지에 적용한 사례는 드물다.

본 연구에서는 개발도상국에서 고흡착 골탄을 제작 생산 할 수 있는 최적 기술조건을 도출하였으며 처리수의 수질 안정화를 위해서 유속 변화에 따른 탁도 및 유기물 제거 경 향을 살펴보았다. 또한, 불소 제거 측면에서 회분기 및 컬럼 실험을 통해 최대 흡착량과 흡착 효율을 비교하였다. 마지 막으로 저에너지 운전을 위한 컬럼의 최적 운전 조건을 결 정하였다.

\section{2. 실험방법}

\section{1. 골탄 제조 방법}

골탄의 흡착 효과는 초기 불소농도, 태우는 온도 및 시간, 골탄의 크기 등에 영향을 미치며 지속적인 연구가 수행되고 있다. ${ }^{19-22)}$ 일반적인 골탄 제조는 대형 가마에 다량의 뼈를 통째로 넣고 장시간 동안 태워 골탄을 생산하지만, 본 연구 에서는 뼈를 씻어 건조시킨 후 내부까지 태워질 수 있도록 절단하고 전기로(LOMF-702, SCI FINETECH, Korea)에서 $350,450,550^{\circ} \mathrm{C}$ 로 온도별로 각각 $1,3,5$ 시간을 태워 골탄 을 제작하여 고흡착 골탄의 최적 조건을 도출하였다. 각 실험 조건에 맞게 태워진 골탄은 에티오피아 골탄 크기와 동일하게 600 2,000 $\mu \mathrm{m}$ 로 체거름하여 흡착 실험에 사용되 었다. 골탄의 크기에 따라서 골탄의 표면적이 변하기 때 문에 불소 흡착 효율에 영향을 미칠 수 있다. 크기가 작은 골탄은 큰 골탄보다 $\mathrm{g}$ 당 표면적이 넓기 때문에 흡착효율이 다르다. 그래서 본 실험에서는 유사한 크기로 골탄을 준비하 여 실험하였다. 실험에 사용한 에티오피아 골탄은 현지 $\mathrm{NGO}$ (non-government organization)에서 생산된 제품이며 본 연구 에서 제작한 골탄은 국내 한우 소뼈를 이용하여 제작하였다.

\section{2. 골탄의 표면분석}

제작된 골탄이 불소 흡착 효과에 어떠한 영향을 미치는 지 표면 분석을 수행하였다. 본 연구에서 제작된 골탄과 에 티오피아 골탄을 주사전자현미경(SEM, Scanning Electron Microscope) (Hitachi S-4800, Hitachi, Japan)을 이용해서 골
탄 표면의 물리화학적 특징을 비교 분석하였다. 또한, 비표 면적 및 기공 부피 분석을 위해서 비표면적분석기(BET, Brunauer-Emmett-Teller) (BELSORP-MAX, BEL, Japan)를 통해 제작된 골탄과 에티오피아 골탄의 표면 성질과 기공 크기가 불소 흡착에 어떠한 영향을 미치는지 알아보았다.

\section{3. 골탄 흡착 실험}

\subsection{1. 회분기 실험}

실험에 사용된 시약은 ACS 등급인 sodium fluoride (NF, Sigma-Aldrich, USA)을 이용하였다. 그리고 3차 증류 장치 (Simpure D330, UMS science, Korea)를 이용해서 $200 \mathrm{mg} / \mathrm{L}$ 의 불소 stock solution을 제조하였다. 골탄을 이용한 불소 흡착 회분기 실험에서는 $50 \mathrm{ml}$ conical tube에 불소 용액을 $5,10,20,30,40,50,100,200 \mathrm{mg} / \mathrm{L}$ 만들어 골탄 $1 \mathrm{~g}$ 씩 각각 넣은 후 회전 혼합기(Tube rotating mixer, DLAB, USA)를 사용하여 kinetic 흡착 실험과 isotherm 흡착 실험을 하였다. 48 시간 동안 총 10 회 걸쳐서 샘플링하였고 잔류된 불소 농 도를 분석하여 골탄에 흡착되는 불소의 영향을 알아보았다. 모든 샘플은 필터의 기공 사이즈가 $0.45 \mu \mathrm{m}$ 로 제작된 주사기 필터로 전처리한 후 분광 광도계(DR5000, $\mathrm{HACH}, \mathrm{USA})$ 를 이용하여 불소 분석을 하였다.

\subsection{2. 컬럼 실험}

제조된 골탄은 불완전 탄화로 인해 일부 유기물이 씻겨져 나올 수 있다. 그리고 골탄의 부스러기가 초기 탁도를 유발 한다. 유입 유속 변화가 유기물, 탁도 그리고 불소 제거에 어떠한 영향을 미치는지 컬럼실험을 통해서 수행하였다. 실 험에 사용된 4개의 컬럼에 제조된 골탄 $70 \mathrm{~g}$ 씩 각각 넣고 $100,200,300,400 \mathrm{~L} / \mathrm{day}$ 의 유속 조건으로 90 분 운전하여 수 행하였다. 초기 불소 농도는 $4.8 \mathrm{mg} / \mathrm{L}$ 에서 시작하였으며 처 리수의 탁도, 유기물, 불소 농도가 유속 변화에 어떠한 영향 을 미치는지 살펴보았다. 처리수 수질 분석은 $0.45 \mu \mathrm{m}$ 주사 기 필터로 전처리한 후 분석하였다. 유속 변화에 따른 컬럼 에서의 압력 변화를 알아보기 위해서 모든 컬럼에 압력계를 달아 압력 변화를 모니터링하였다. 빠른 유속일 경우 높은 압력으로 에너지가 많이 소모되는 만큼 처리량이 많고 골탄 의 불소 파과속도가 빠르다. 그렇기 때문에 적절한 유속에 서의 유량 확보를 알기 위해서 유속 변화에 따른 압력 변화 를 처리량으로 비교 분석하였다. Table 1은 실험에 사용된 컬럼의 운전 조건이다.

\section{3. 결과 및 고찰}

\section{1. 고흡착 골탄 제조}

\subsection{1. 조건별 골탄 제조 결과}

최적의 골탄 생산 조건을 도출하기 위해서 뼈의 태우는 온도와 시간 조건에 따른 처리수의 탁도, TOC, 불소의 수질 
Table 1. Operating condition of column test.

\begin{tabular}{cc} 
Dimension & Specification \\
Diameter & $1.25 \mathrm{~cm}$ \\
Length & $48 \mathrm{~cm}$ \\
Bone char & $70 \mathrm{~g}$ \\
Initial fluoride concentration & $4.8 \mathrm{mg} / \mathrm{L}$ \\
Type & Cylinder \\
Material & Transparent acrylic \\
\hline
\end{tabular}

결과를 Table 2에서 보여주고 있다. 온도와 태우는 시간이 증가할수록 탁도와 TOC 값이 떨어지며, 불소 흡착력이 낮 아지는 경향을 알 수 있었다. $350^{\circ} \mathrm{C}, 1$ 시간에서 불소 흡착 력이 가장 높은 $5.1 \mathrm{mg} \mathrm{F} / \mathrm{g}$ 이지만, 탁도와 TOC 값도 높기 때문에 수질 조건에 적합하지 않다. Fig.1에서 보여준 것과 같이 낮은 온도와 짧은 시간은 뼈 내·외부에 존재하는 유기 물이 불완전 연소로 인해 검붉은 잔류 물질로 존재하기 때문 에 식수로서는 적합하지 않다. $450,550^{\circ} \mathrm{C}$ 와 3,5 시간 조건은 $350^{\circ} \mathrm{C}$ 보다 불소 흡착 효율이 낮지만, 탁도, TOC 값이 낮아 수질에 적합했다. 불소 흡착 효율에서는 $450^{\circ} \mathrm{C}$ 가 $550^{\circ} \mathrm{C}$ 보다
높고 3 시간이 5 시간보다 효과적이기 때문에 최적 골탄 제조 조건은 $450^{\circ} \mathrm{C}$ 에서 3 시간으로 결정되었다. $550^{\circ} \mathrm{C}$ 이상에서는 불소를 흡착하는 골탄의 표면 hydroxyapatite가 붕괴하여 오 히려 흡착 효율이 떨어지는 것으로 보고되고 있다. ${ }^{22)}$

\subsection{2. 골탄 표면 분석결과}

연구에서 사용된 골탄과 에티오피아에서 생산한 골탄의 표면 분석을 통해서 흡착 효율에 대한 영향을 알아보았다. Fig. 2(a)는 본 연구에서 제작한 골탄의 표면이며, Fig. 2(b) 는 에티오피아에서 생산한 골탄의 표면 모습이다. Fig. 2(a) 는 (b)보다 표면 거칠기의 모습이 일정하며 균일하고 날카 로운 모습을 보여준다. 이러한 거칠기는 골탄의 비표면적에 영향을 미치기 때문에 흡착에도 영향을 미치는 것으로 보고 되고 있다. ${ }^{23)}$ 또한, 골탄의 비표면적에서도 기공의 면적과 부피에 따라서 불소 흡착 효율에 영향을 미치는 것으로 사 료된다. Table 3은 제작된 골탄과 에티오피아 골탄을 이용 한 비표면적 분석 결과이다. 제작된 골탄의 비표면적은 70.9 $\mathrm{m}^{2} / \mathrm{g}$ 이며 에티오피아 골탄은 $39.8 \mathrm{~m}^{2} / \mathrm{g}$ 이다. 제작된 골탄의 비표면적이 에티오피아 골탄보다 약 2 배 큰 것으로 확인되

Table 2. Turbidity, TOC, and fluoride results according to temperature and time.

\begin{tabular}{|c|c|c|c|c|}
\hline \multirow{2}{*}{ Parameter } & \multirow{2}{*}{ Heating time (h) } & \multicolumn{3}{|c|}{ Heating temperature } \\
\hline & & $350^{\circ} \mathrm{C}$ & $450^{\circ} \mathrm{C}$ & $550^{\circ} \mathrm{C}$ \\
\hline \multirow{3}{*}{$\begin{array}{l}\text { Turbidity } \\
\text { (NTU) }\end{array}$} & 1 & 55.8 & 17.1 & 11.9 \\
\hline & 3 & 25.2 & 1.8 & 2.1 \\
\hline & 5 & 16.9 & 1.8 & 3.1 \\
\hline \multirow{3}{*}{$\begin{array}{c}\text { TOC } \\
(\mathrm{mg} / \mathrm{L})\end{array}$} & 1 & 86.5 & 11.3 & 4.9 \\
\hline & 3 & 46.9 & 1.9 & 0.4 \\
\hline & 5 & 14.6 & 1.5 & 0.7 \\
\hline \multirow{3}{*}{$\begin{array}{l}\text { Fluoride } \\
\text { (mg F/g) }\end{array}$} & 1 & 5.1 & 3.8 & 2.8 \\
\hline & 3 & 4.6 & 3.7 & 0.8 \\
\hline & 5 & 4.6 & 2.5 & 0.4 \\
\hline
\end{tabular}

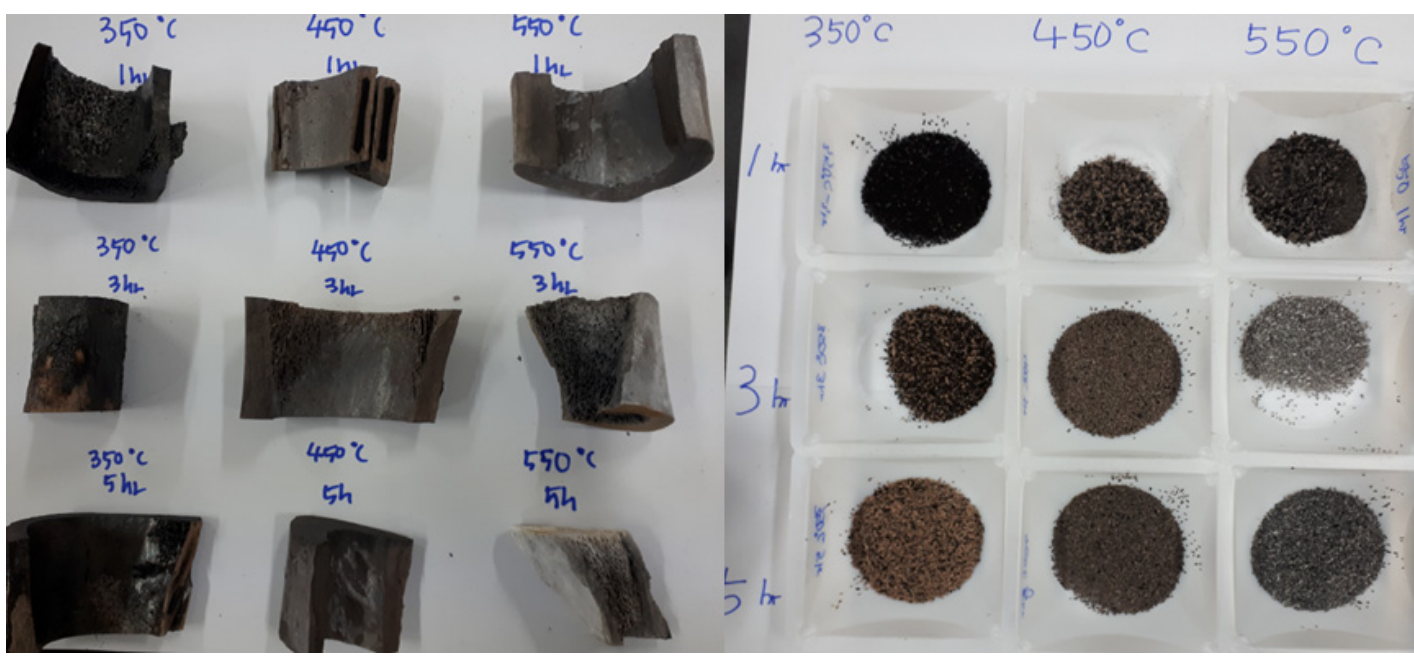

Fig. 1. Bone char made by burning 1 hour, 3 hours and 5 hours for every $350^{\circ} \mathrm{C}, 450^{\circ} \mathrm{C}$, and $550^{\circ} \mathrm{C}$. 
Table 3. Surface analysis of produced bone char and Ethiopia bone char.

\begin{tabular}{ccc} 
Parameter & Produced bone char & Ethiopia bone char \\
BET $\left(\mathrm{m}^{2} / \mathrm{g}\right)$ & 70.9 & 39.8 \\
Pore volume $\left(\mathrm{cm}^{3} / \mathrm{g}\right)$ & 0.30 & 0.23 \\
Pore diameter $\left(\mathrm{cm}^{3} / \mathrm{g}\right)$ & 17.1 & 23.1 \\
\hline
\end{tabular}
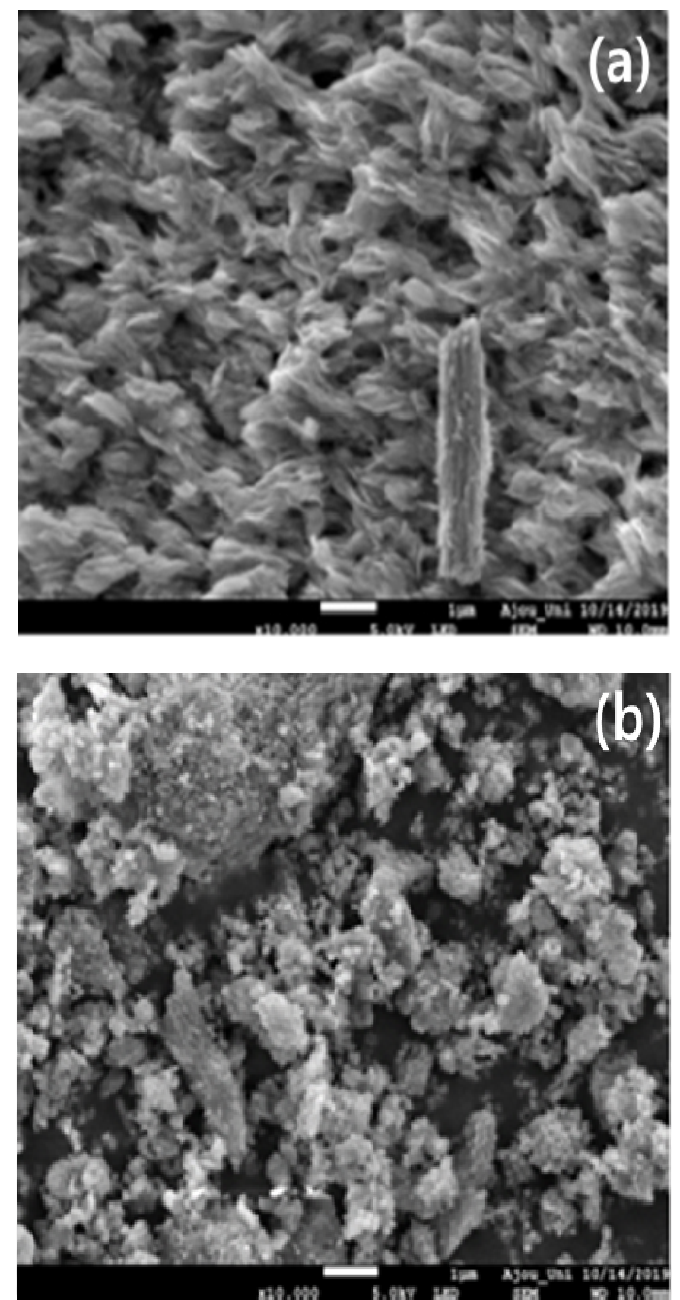

Fig. 2. Result of SEM analysis. (a) Produced bone char, (b) Ethiopia bone char.

었다. 비표면적이 높다는 것은 골탄 표면에 불소를 흡착할 수 있는 공간이 많아 흡착 효율이 크다는 것을 알 수 있다. 또한, 기공 부피에서도 제작된 골탄이 크다는 것을 알 수 있 었다. 하지만, 기공 직경은 에티오피아 골탄이 $23.1 \mathrm{~cm}^{3} / \mathrm{g}$ 이 며 제작된 골탄이 $17.1 \mathrm{~cm}^{3} / \mathrm{g}$ 로 에티오피아 골탄이 높게 나 왔다. 기공 직경보다는 비표면적과 기공 부피가 흡착에 영 향을 미칠 것으로 사료된다.

\section{2. 회분식 실험결과}

\subsection{1. 불소흡착 실험결과}

불소 제거 실험을 위해서 제작된 골탄을 사용하여 다양한

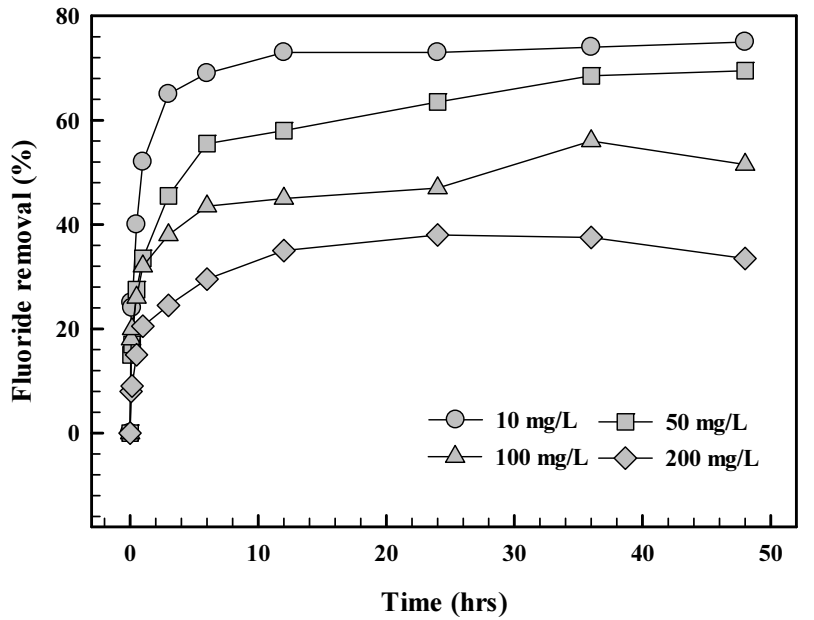

Fig. 3. Fluoride removal (\%) according to changing fluoride concentration (10,50, 100, and $200 \mathrm{mg} / \mathrm{L})$.

불소 농도 조건에서 kinetic 흡착 실험과 isotherm 흡착 실험 을 수행하였다. Fig.3에서는 10, 50, 100, $200 \mathrm{mg} / \mathrm{L}$ 의 불소 농도 조건에서 제작된 골탄을 이용한 kinetic 흡착 실험을 보여주고 있다. 모든 조건에서 운전 직후 빠른 불소 흡착이 진행되는 경향을 확인할 수 있었다. 그리고 낮은 불소 농도 인 $10 \mathrm{mg} / \mathrm{L}$ 에서는 12 시간 만에 흡착 평형에 도달하였고 불 소 제거율이 $73 \%$ 였다. 높은 불소 농도인 $200 \mathrm{mg} / \mathrm{L}$ 에서는 24 시간 만에 흡착 평형에 도달하였으며 불소 제거율이 $38 \%$ 로 나타났다. 결과적으로 낮은 불소 농도에서 흡착 평형이 빠르고 불소 제거율이 높다는 것을 알 수 있었다. 제작된 골 탄의 최대 흡착량은 불소원수 농도 $10 \mathrm{mg} / \mathrm{L}$ 에서 $7.3 \mathrm{mg}$ $\mathrm{F} / \mathrm{g}$ 으로 확인되었으며 에티오피아 골탄을 이용한 자체 흡착 실험결과에서는 최대 흡착량이 약 $1 \mathrm{mg} \mathrm{F} / \mathrm{g}$ 으로 확인되었 다. ${ }^{24)}$ 이는 제작된 골탄의 불소흡착효율이 에티오피아 골탄 보다 약 7 배 높다는 것을 알 수 있었다. 지하수 불소 농도가 높아지면 최대 흡착량도 증가하지만, 대체적으로 제거율이 낮아지기 때문에 낮은 불소 농도에서의 골탄 이용이 효과적 이다. 제작된 골탄을 이용한 isotherm 흡착 실험을 Fig.4에 서 보여주고 있다. $133 \mathrm{mg} / \mathrm{L}$ 의 평형 농도에서 불소 흡착량 은 $67 \mathrm{mg} \mathrm{F} / \mathrm{g}$ 이며 $2.0 \mathrm{mg} / \mathrm{L}$ 의 평형 농도에서 불소 흡착량 은 증가하다가 $5.7 \mathrm{mg} / \mathrm{L}$ 의 흡착 평형 농도에서 최대 흡착량 이 점차 감소되는 경향을 보여주고 있다. 그렇기 때문에 불 소 흡착 농도는 낮은 평형 농도에서 빠르게 진행되는 것을 알 수 있다. 제작된 골탄을 이용한 개도국 지하수 불소 제거 는 높은 제거효율을 보여주는 낮은 평형 농도에서 적절하 다. 이는 불소 농도가 낮은 지하수에 제작된 골탄이 적합한 것으로 사료된다.

\section{3. 컬럼 실험결과}

\subsection{1. 탁도 및 TOC 결과}

컬럼 운전시 초기 처리수 탁도 및 TOC 변화를 다양한 유 


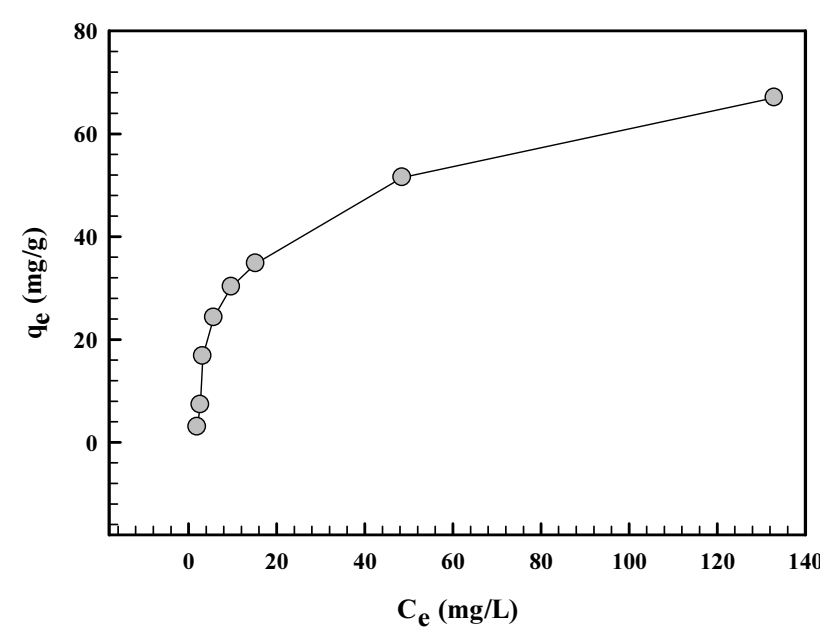

Fig. 4. Adsorption isotherm of produced bone char.

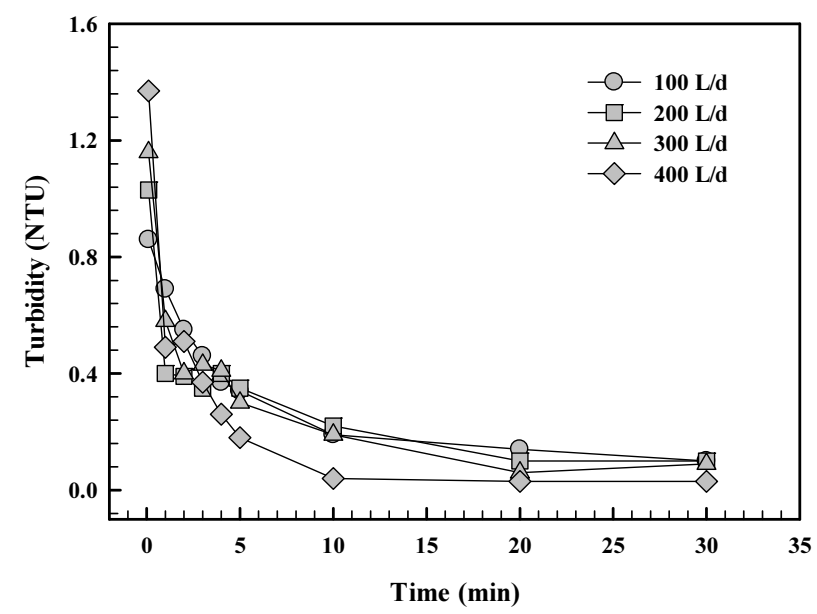

Fig. 5. Turbidity result according to flow-rate $(100,200,300$, and $400 \mathrm{~L} / \mathrm{d})$.

량으로 모니터링하였다. Fig.5에서는 운전 3분 후 모든 유 량 조건에서 우리나라의 먹는 물 탁도 기준인 $0.5 \mathrm{NTU}$ 이 하의 일정한 값을 얻을 수 있었다. 그래서 $100,200,300$, $400 \mathrm{~L} / \mathrm{d}$ 에서의 탁도는 3 분 후 각각 $0.46,0.35,0.43,0.37$ $\mathrm{NTU}$ 로 알 수 있었다. 그리고 각 유량 조건에서 탁도 0.5 $\mathrm{NTU}$ 에 도달하는 시간은 $3,1,2,1$ 분으로 알 수 있으며 처 리수는 각각 $0.20,0.13,0.52,0.27 \mathrm{~L} / \mathrm{min}$ 이였다. 가장 물소 비가 적은 것은 $200 \mathrm{~L} / \mathrm{d}$ 로 확인되었다. 운전 후 0.5 분에서는 $100,200,300,400 \mathrm{~L} / \mathrm{d}$ 의 처리수 탁도 값이 각각 $0.86,1.03$, $1.16,1.37 \mathrm{NTU}$ 로 나타났으며 $400 \mathrm{~L} / \mathrm{d}$ 에서 높은 탁도 값을 보여주었다. 이는 빠른 유속으로 인해 컬럼 안에 잔존하고 있던 미세한 입자들이 초기에 유출됨에 따라 탁도에 영향을 미친 것으로 사료된다. 또한, $400 \mathrm{~L} / \mathrm{d}$ 에서는 상대적으로 탁 도 제거가 빨라 10 분 후 $0.04 \mathrm{NTU}$ 로 확인된 반면 100,200 , $300 \mathrm{~L} / \mathrm{d}$ 에서는 각각 $0.19,0.22,0.19 \mathrm{NTU}$ 로 유사한 값을 보 여주었다. 많은 유량이 빠른 유속을 유발하여 탁도 제거 측 면에서 효과적일 수 있지만, 물량 소비가 크다는 단점이 있

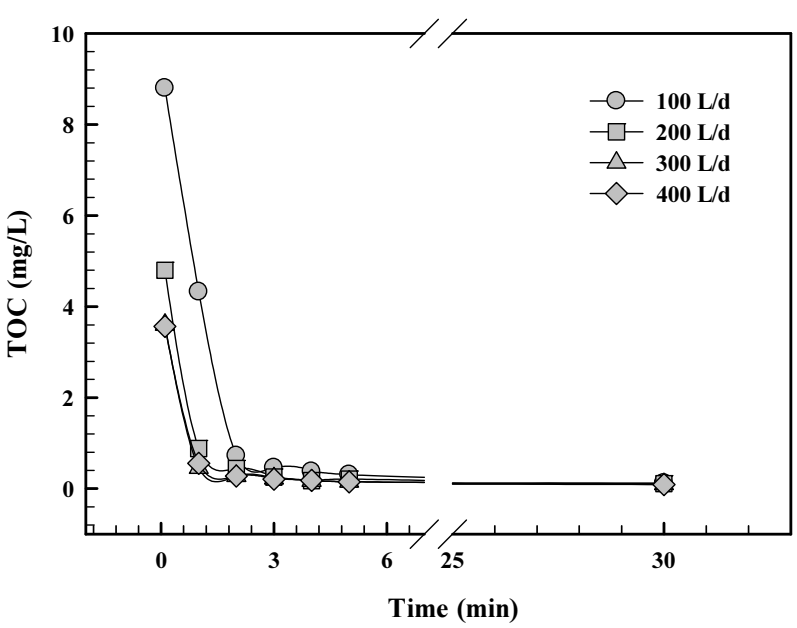

Fig. 6. TOC result according to flow-rate $(100,200,300$, and $400 \mathrm{~L} / \mathrm{d})$.

다. 이는 높은 유속일수록 탁도를 빠르게 떨어질 수 있지만, 식수로 이용되는 처리수량이 소모되기 때문에 적절한 운전 인자가 요구된다. 운전 1 분 후 $100,200,300,400 \mathrm{~L} / \mathrm{d}$ 의 탁 도는 각각 $0.69,0.40,0.58,0.49 \mathrm{NTU}$ 이므로 초기 미세입자 제거 측면에서 가장 탁도가 낮은 $200 \mathrm{~L} / \mathrm{d}$ 가 효과적인 운전 인자이다. Fig.6은 모든 유량 조건에서 TOC 값이 3분 안에 급격히 떨어지는 것을 보여주고 있다. 그리고 앞선 탁도 결 과와 상반되게 운전 0.5 분에서 $100,200,300,400 \mathrm{~L} / \mathrm{d}$ 의 $\mathrm{TOC}$ 값이 각각 $8.80,4.79,3.60,3.56 \mathrm{mg} / \mathrm{L}$ 이며 낮은 유량 일수록 높은 $\mathrm{TOC}$ 을 보여주었다. $100 \mathrm{~L} / \mathrm{d}$ 에서는 2 분 후 안 정적인 $\mathrm{TOC}$ 값을 보인 반면 $200,300,400 \mathrm{~L} / \mathrm{d}$ 에서는 1 분 후 안정적인 TOC 값을 보여주고 있다. 초기 TOC 제거 측 면에서 $200,300,400 \mathrm{~L} / \mathrm{d}$ 이 유사한 제거 경향을 보여주고 있기 때문에 효과적인 TOC 제거는 탁도 제거와 함께 운영 함에 있어서 $200 \mathrm{~L} / \mathrm{d}$ 가 최적 운전 인자이다. 이처럼 $\mathrm{TOC}$ 가 낮아지는 이유는 골탄 표면에서 떨어져 나간 입자성 물질에 의한 영향으로 알 수 있다.

\subsection{2. 불소제거 결과}

본 연구에서 제작된 골탄을 이용하여 컬럼의 운전시간과 bed volume이 유량 변화에 따라 불소 농도에 어떠한 영향 을 미치는지 알아보았다. Fig. 7은 운전시간과 유량 변화에 미치는 불소 농도 결과를 보여주고 있으며 먹는 물 불소 수 질 기준인 $1.5 \mathrm{mg} / \mathrm{L}$ 를 점선으로 표시하였다. 유량이 클수록 유속이 증가되어 골탄이 파과되는 속도가 빠르고 불소 수질 기준에 빠르게 접근하는 것을 알 수 있었다. 빠른 파과곡선 은 골탄 크기 결정에 있어서 공극률이 주된 원인으로 알려 져 있다. ${ }^{23)}$ 그렇기 때문에 유사한 골탄 크기를 이용하고 있 는 에티오피아 현지에서도 본 실험과 같은 조건에서 비슷한 결과를 초래할 것으로 사료된다. $100,200,300,400 \mathrm{~L} / \mathrm{d}$ 로 운전할 때 불소 $1.5 \mathrm{mg} / \mathrm{L}$ 가 초과되는 시간은 각각 80,30 , 


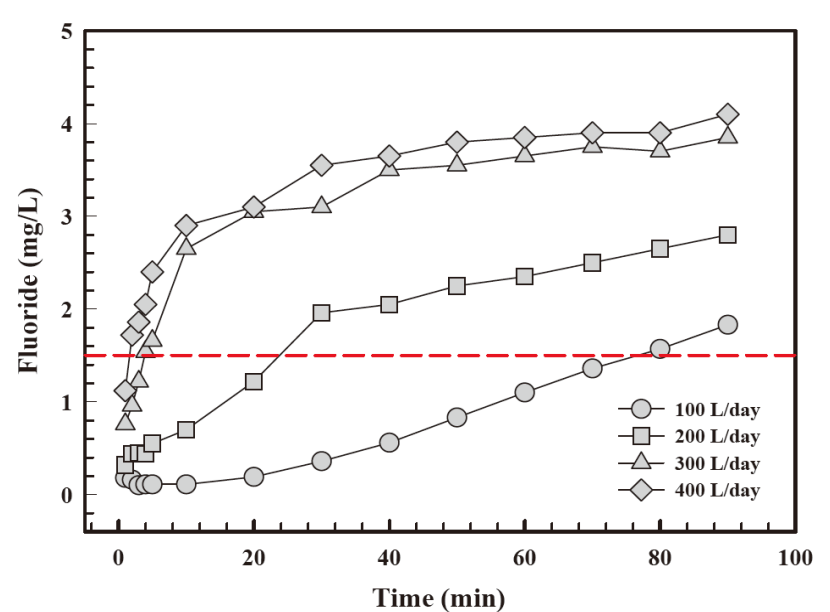

Fig. 7. Result of fluoride removal according to time in 100 , 200,300 , and $400 \mathrm{~L} / \mathrm{d}$.

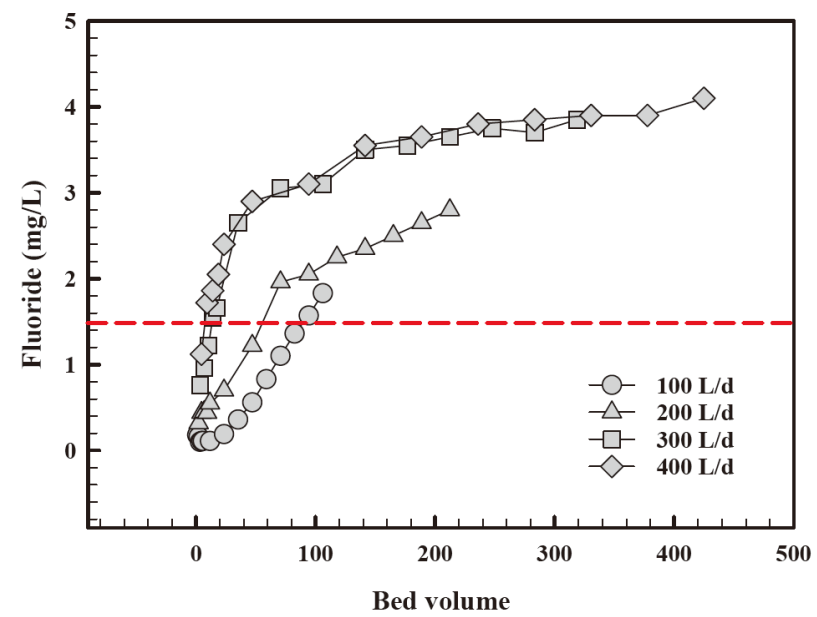

Fig. 8. Result of fluoride removal according to bed volume in $100,200,300$, and $400 \mathrm{~L} / \mathrm{d}$.

4,2 분으로 나타내었다. 특히 $300,400 \mathrm{~L} / \mathrm{d}$ 에서 빠른 시간에 처리수 불소 농도인 $1.5 \mathrm{mg} / \mathrm{L}$ 가 초과하지만 $100,200 \mathrm{~L} / \mathrm{d}$ 에 서는 상대적으로 불소 농도가 느리게 증가되어 $400 \mathrm{~L} / \mathrm{d}$ 보다 약 40,20 배의 운영 시간을 늘릴 수 있다. 에티오피아 현지 에서는 고속운전보다 저속운전으로 컬럼을 운영하는 것이 효과적인 방법이다. Fig. 8은 bed volume에 따른 불소 농 도 변화를 보여주고 있다. $100,200,300,400 \mathrm{~L} / \mathrm{d}$ 에서 최대 bed volume은 90분 후 각각 106.2, 212.4, 318.6, 424.8이며 $1.5 \mathrm{mg} / \mathrm{L}$ 가 초과되는 불소 수질 기준에서의 bed volume은 각각 $94.4,70.8,14.1,9.4$ 이다. $100 \mathrm{~L} / \mathrm{d}$ 는 적은 유량으로 인 해 bed volume이 큰 반면 많은 유량인 $300,400 \mathrm{~L} / \mathrm{d}$ 에서는 파과속도가 빨라 bed volume이 작고 불소 제거 경향도 유 사한 값을 보여주고 있다. 불소 수질 기준으로 식수를 공급 할 때 $100 \mathrm{~L} / \mathrm{d}$ 는 $400 \mathrm{~L} / \mathrm{d}$ 보다 10 배 많은 bed volume을 확보 할 수 있다. 그래서 실험에 사용된 컬럼은 높은 유량보다는 낮은 유량에서 운전하는 것이 유리하다. $300 \mathrm{~L} / \mathrm{d}$ 와 $400 \mathrm{~L} / \mathrm{d}$ 의 높은 유량에서는 에너지 절감을 위해서 $300 \mathrm{~L} / \mathrm{d}$ 가 적합

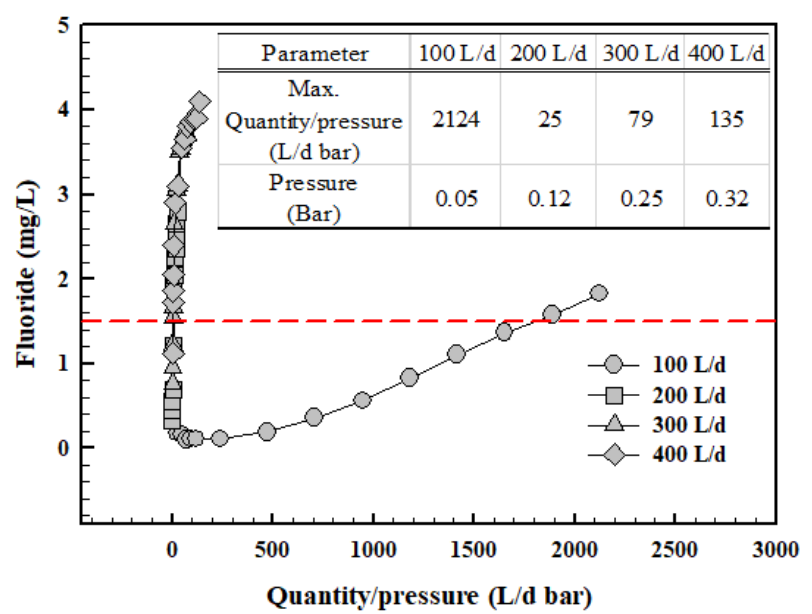

Fig. 9. Result of fluoride removal according to quantity/pressure in $100,200,300$, and $400 \mathrm{~L} / \mathrm{d}$.

하다는 것을 보여주고 있다. 많은 식수를 요구하는 현지 지 역에서는 앞서 거론한 것과 같이 골탄의 크기를 작게 제작 하여 낮은 유량으로 운전하면 높은 bed volume을 얻을 수 있다.

\subsection{3. 최적 운전조건 도출}

유량이 증가하면 컬럼 내 압력이 증가하기 때문에 에너지 손실이 발생할 뿐만 아니라 식수 공급량에도 영향을 미친 다. 제작된 골탄을 이용한 최적의 컬럼 운전 조건을 도출하 였으며 Fig.9는 컬럼 내 압력 발생에 따른 처리수량을 불소 제거 경향으로 보여주고 있다. 유량이 증가할수록 처리수량 도 증가하고 컬럼 내 발생되는 최대 압력도 $100,200,300$, $400 \mathrm{~L} / \mathrm{d}$ 에서 각각 $0.05,0.12,0.25,0.32 \mathrm{bar}$ 로 증가하였다. 하지만, 이러한 컬럼 내 에너지 손실을 고려할 때 알 수 있 는 최대 처리수의 운전조건은 $100>400>300>200 \mathrm{~L} / \mathrm{d}$ 의 순이며 최대 처리수는 각각 $2,124,25,79,135 \mathrm{~L} / \mathrm{d}$ bar로 확인되었다. 그리고 먹는물 불소 수질 기준인 $1.5 \mathrm{mg} / \mathrm{L}$ 에서 는 $100,200,300,400 \mathrm{~L} / \mathrm{d}$ 조건에서 처리수가 각각 1,888 , $8,3,3 \mathrm{~L} / \mathrm{d}$ bar로 확인되었다. 제작된 골탄을 이용한 처리수 확보에 있어서 고유량인 $400 \mathrm{~L} / \mathrm{d}$ 보다 저유량인 $100 \mathrm{~L} / \mathrm{d}$ 가 약 630배 많은 처리수를 확보할 수 있었다. 따라서 본 연구 에서는 제작된 골탄을 이용하여 불소를 제거할 때 고유량 보다는 저유량으로 운전하여 사용하는 것이 에너지 절감과 처리수 확보에 있어서 더욱 효과적인 운전 조건이다.

\section{4. 결론}

1) 제작된 골탄은 에티오피아 골탄보다 거칠고 비표면적 이 넓어 불소 흡착효율이 높은 특징을 가지고 있다. 이는 최 적화된 골탄 제작 조건을 통해서 얻은 결과이며 현지에서 동일한 방법으로 골탄을 생산할 경우 고흡착 골탄을 이용할 수 있다. 
2) 제작된 골탄은 기존 골탄보다 불소 흡착 효율이 10 $\mathrm{mg} / \mathrm{L}$ 에서 약 7배 높았으며 탁도 및 유기물 제거에서도 200 $\mathrm{L} / \mathrm{day}$ 에서 1 분이 최적 운전 인자임을 알 수 있었다.

3) 컬럼운전을 통한 불소 제거 결과 값을 운전시간, bed volume, 에너지 효율 조건으로 비교할 때 $100 \mathrm{~L} / \mathrm{d}$ 는 400 $\mathrm{L} / \mathrm{d}$ 보다 각각 80 배, 10 배, 1.6 배의 효과를 얻을 수 있었다. 4) 저유량 운전이 고유량 운전보다 에너지 절감과 처리수 확보에 있어서 효과적인 운전 조건으로 알 수 있었다. 그래 서 골탄을 이용한 현지 컬럼 운전에 있어서 많은 에너지가 소요되는 시설보다는 적은 에너지를 통해서 운영할 수 있는 시설이 더욱 효과적이다.

\section{Acknowledgement}

본 연구는 한국연구재단의 연구비 지원으로 수행되었습니 다(과제번호: 2017K1A3A9A04013880). 이에 감사드립니다.

\section{References}

1. K. R. Nair, J. N. Gitonga, The occurrence and distribution of fluoride in groundwater of Kenya, Challenges in African Hydrology and Water Resources, in Proceedings of the Harare Symposium, 144, pp. 75-86(1984).

2. J. Malago, E. Makoba, A. N. N. Muzuka, Fluoride levels in surface and groundwater in Africa: a review, Am. J. Water. Sci. Eng., 3(1), 1-17(2017).

3. Y. Li, C. Liang, C. W. Slemenda, R. Ji, S. Sun, J. Cao, C. L. Emsley, F. Ma, Y. Wu, P. Ying, S. Gao, W. Zhang, B. P. Katz, S. Niu, S. Cao, C. C. Johnston Jr, Effect of long-term exposure to fluoride in drinking water on risks of bone fractures, J. Bone Miner. Res., 16(5), 932-939(2001).

4. K. M. K. Kut, A. Sarswat, A. Srivastava, C. U. Pittman Jr, A review of fluoride in african groundwater and local remediation methods, Groundw. Sustain. Dev., 2-3, 190-212 (2016).

5. M. Vithanage, P. Bhattacharya, Fluoride in the environment: sources, distribution and defluoridation, Environ. Chem. Lett., 13, 131-147(2015).

6. R. Liu, L. Zhu, W. Gong, H. Lan, H. Liu, J. Qu, Effects of fluoride on coagulation performance of aluminum chloride towards Kaolin suspension, Colloids Surf. A-Physicochem. Eng. Asp., 421, 84-90(2013).

7. Y. Ma, F. Shi, X. Zheng, J. Ma, C. Gao, Removal of fluoride from aqueous solution using granular acid-treated bentonite (GHB): batch and column studies, J. Hazard. Mater., 185, 1073-1080(2011).

8. J. Hu, D. Wu, R. Rao, R. Liu, W. Lai, Adsorption kinetics of fluoride on bone char and its regeneration, Environ. Prot. Eng., 43(3), 93-112(2017).

9. M. Mohapatra, S. Anand, B. K. Mishra, D. E. Giles, P. Singh, Review of fluoride removal from drinking water, J.
Environ. Manag., 91(1), 67-77(2009).

10. P. Loganathan, S. Vigneswaran, J. Kandasamy, R. Naidu, Defluoridation of drinking water using adsorption processes, J. Hazard. Mater., 248-249, 1-19(2013).

11. J. C. Moreno-Piraján, L. Giraldo, V. S. García-Cuello, Study of the textural properties of bovine bones char under different conditions, J. Water. Res. Prot., 3(3), 176-181(2011).

12. N. A. Medellin-Castillo, E. Padilla-Ortega, L. D. Tovar-García, R. Leyva-Ramos, R. Ocampo-Pérez, F. Carrasco-Marín, M. S. Berber-Mendoza, Removal of fluoride from aqueous solution using acid and thermally treated bone char, Adsorption, 22, 951-961(2016).

13. A. Aklil, M. Mouflih, S. Sebti, Removal of heavy metal ions from water by using calcined phosphate as a new adsorbent, J. Hazard. Mater., 112(3), 183-190(2004).

14. R. Leyva-Ramos, J. Rivera-Utrilla, N. A. Medllin-Castilo, M. Sanchez-polo, Kinetic modeling of fluoride adsorption from aqueous solution onto bone char, Chem. Eng. J., 158(3), 458-467(2010).

15. N. A. Medellin-Castillo, R. Leyva-Ramos, R. Ocampo-Perez, R. F. Garcia de la Cruz, A. Aragon-Piña, J. M. Martinez-Rosales, R. M. Guerrero-Coronado, L. Fuentes-Rubio, Adsorption of fluoride from water solution on bone char, Ind. Eng. Chem. Res., 46(26), 9205-9212(2007).

16. N. M. Zúñiga-Muro, A. Bonilla-Petriciolet, D. I. Mendoza-Castillo, H. E. Reynel-Ávila, J. C. Tapia-Picazo, Fluoride adsorption properties of cerium-containing bone char, J. Fluorine Chem., 197, 63-73(2017).

17. C. K. Rojas-Mayorga, A. Bonilla-Petriciolet, I. A. AguayoVillarreal, V. Hernandez-Montoya, M. Moreno-Virgen, R. Tovar-Gómez, M. A. Montes-Morán, Optimization of pyrolysis conditions and adsorption properties of bone char for fluoride removal from water, J. Anal. Appl. Pyrol., 104, 10-18(2013).

18. L. Delgadillo-Velasco, V. Hernández-Montoya, F. J. Cervantes, M. A. Montes-Morán, D. Lira-Berlanga, Bone char with antibacterial properties for fluoride removal: preparation, characterization and water treatment, J. Environ. Manag., 201, 277-285(2017).

19. N. A. Medellin-Castilloa, R. Leyva-Ramos, E. Padilla Ortega, R. Pcampo Perez, J. V. Flores-Cano, M. S. Berber Mendoza, Adsorption capacity of bone char for removing fluoride from water solution. Role of hydroxyapatite content, adsorption mechanism and competing anions, J. Ind. Eng. Chem., 20(6), 4014-4021(2014).

20. G. E. J. Poinern, M. K. Ghosh, Y. J. Ng, T. B. Issa, S. Anand, P. Singh, Defluoridation behavior of nanostructured hydroxyapatite synthesized through an ultrasonic and microwave combined technique, J. Hazard. Mater., 185(1), 29-37(2011).

21. M. Mourabet, A. E. Rhilassi, H. E. Boujaady, M. B. Ziatni, R. E. Hamri, A. Taitai, Removal of fluoride from aqueous solution by adsorption on hydroxyapatite (HAp) using response surface methodology, J. Saudi. Chem. Soc., 19(6), 603-615(2015).

22. S. M. Kariuki, M. S. Ngari, W. J. Mavura, M. S. Ollengo, 
P. O. Ongoma, Effect of essential mineral ions from aqueous media on adsorption of fluoride by bone char, J. Environ. Sci. Toxicol. Food Technol., 9(5), 9-17(2015).

23. E. M. Nigir, A. Bhatnagar, S. D. F. Rocha, Thermal regeneration process of bone char used in the fluoride removal from aqueous solution, J. Clean. Prod., 142(4), 3558-3570(2017).

24. S. S. A. Alkurdi, R. A. Al-juboori, J. Bundschuh, I. Hamawand, Bone char as a green sorbent for removing health threatening fluoride from drinking water, Environ.. Int., 127, 704-719(2019).

\section{Authors}

\section{Min-Soo Maeng}

Department of Environmental and Safety Engineering, Ajou University, Ph.D., ORCID (1) 0000-0002-6232-9368

\section{Jung-Seop Byun}

Department of Environmental and Safety Engineering, Ajou University, Master Candidate

\section{Hyo-Jin Park}

Department of Environmental and Safety Engineering, Ajou University, Master Candidate

\section{Gwy-Am Shin}

Department of Environmental and Safety Engineering, Ajou University, Professor, ORCID(D) 0000-0002-2858-6758 